\title{
Propuesta de programa para la aplicación de vacuna anti-COVID-19 en menores de edad
}

\section{Proposal of a program for applying the COVID-19 vaccine in minors}

José L. García-Vigil*

Universidad Nacional Autónoma de México, Facultad de Medicina, Ciudad de México, México

El plan federal para la aplicación de la vacuna contra COVID-19 me parece ético, apegado a derechos humanos y con fundamento en los factores de riesgo mayores ya identificados en la población mexicana y ajustados por distribución etaria. A casi 11 meses de duración de la pandemia en México, la evolución y resultados epidemiológicos reales, que no estimados, indican la presencia de mutaciones genéticas en SARS-CoV-2, que aumentan $\sim 70 \%$ la capacidad de contagio del virus, el cual infecta cada vez más a niños y jóvenes. Por ello es, quizás, el momento de ajustar el programa de aplicación de la vacuna y reorientarlo hacia los grupos de menor edad, empezando con los de riesgo conocido, con mayor razón dado que, según el plan inicial, serán los últimos por vacunar. Por otro lado, en la población menor de 18 años, la industria farmacéutica no ha recomendado la aplicación de ninguna de las vacunas autorizadas, por lo que sería conveniente aprobarlas como tratamiento preventivo de emergencia y hacer ensayos clínicos con dicho fin en ese grupo de edad., ${ }^{1,2}$

\section{Bibliografía}

1. U. S. Food and Drug Administration [Internet]. EE. UU.: FDA briefing document Pfizer-BioNTech COVID-19 vaccine; 2020.

2. Centers for Disease Control and Prevention [Internet]. EEUU: Vaccines and immunization. Moderna vaccine; 2021.
Gac Med Mex. 2021:157:464

Disponible en PubMed www.gacetamedicademexico.com 0016-3813/@ 2021 Academia Nacional de Medicina de México, A.C. Publicado por Permanyer. Este es un artículo open access bajo la licencia CC BY-NC-ND (http://creativecommons.org/licenses/by-nc-nd/4.0/). 